\title{
Detection of estrogenic hormones using plasmonic nanostructures
}

\author{
Ili F. Mohamad Ali Nasri, ${ }^{\dagger}, \uparrow$ Nigel P. Johnson, ${ }^{\dagger}$ Graham J. Sharp, ${ }^{\dagger}$ Richard M. \\ De La Rue, ${ }^{\dagger}$ Marc Sorel, ${ }^{\dagger}$ and Caroline Gauchotte-Lindsay ${ }^{*, \dagger}$ \\ $\dagger$ Electronics and Nanoscale Engineering, School of Engineering, University of Glasgow, \\ Glasgow, G12 8LT United Kingdom \\ $\ddagger$ Infrastructure and Environment, School of Engineering, University of Glasgow, G12 8LT \\ United Kingdom \\ \University Kuala Lumpur Malaysian Institute of Aviation Technology (UniKL MIAT) \\ Jalan Jenderam Hulu, Jenderam Hulu, 43800, Dengkil, Selangor, Malaysia \\ E-mail: Caroline.Gauchotte-Lindsay@glasgow.ac.uk \\ Phone: +44 (0)1413303842
}

\begin{abstract}
Due to their sensitivity and flexibility, metamaterial structures such as nanoantennas have widely been employed as label-free optical sensors for organic compounds. Detection has so far mostly exploited sensors with a single plasmonic resonance. By optimising the geometry of asymmetric split-H (ASH) resonators fabricated on zinc selenide, we have produced a total of four distinct plasmonic resonances that could be matched with six molecular vibration wavelengths (for $\mathrm{O}-\mathrm{H}, \mathrm{C}-\mathrm{H}, \mathrm{C}=\mathrm{O}, \mathrm{C}=\mathrm{C}, \mathrm{C} \equiv \mathrm{C}-\mathrm{H}$ and $\mathrm{C}-\mathrm{C}$ bonds) which are relevant to the detection of four estrogenic hormones: estrone (E1), 17 $\beta$-estradiol (E2), estriol (E3) and synthetic estrogen; $17 \alpha$-ethinyl estradiol (EE2). Specifically, sensitivities of $363 \mathrm{~nm} / \mathrm{RIU}$ and $636 \mathrm{~nm} / \mathrm{RIU}$ were achieved from the deposition of $\mathrm{E} 2$ on $\mathrm{ASH}_{1}(2 \mu \mathrm{m}$ and $4 \mu \mathrm{m})$ and $\mathrm{ASH}_{2}(5 \mu \mathrm{m}$ and $8 \mu \mathrm{m})$ respectively. The
\end{abstract}


amplitudes of the molecular vibrational resonances were also around 500 times greater when matched with the plasmonic resonances of the ASHs as compared with deposition on bulk ZnSe substrates. Finally, when mixtures of two hormones were deposited on the nanoantennas, the molar ratio for each of the hormones could also be calculated by using the peak intensities for the different molecular vibration wavelengths. By engineering the spectral response of ASH resonators to match specific estrogenic fingerprints, the work paves the way for the development of metamaterial sensors with better specificity and enhanced functionalities.

\section{Abbreviations}

Mid-IR, FTIR, E1, E2, E3, EE2, ASH, ZnSe, FDTD, EtOH

\section{Keywords}

Plasmonic nanostructures, localized surface plasmon resonance (LSPR), Surface-Enhanced InfraRed Absorption (SEIRA), estrogen, $17 \beta$ - estradiol, estrone, estriol, $17 \alpha$-ethinyl estradiol

\section{Introduction}

Estrogenic hormones are a class of endocrine-disrupting compounds (EDC) have been found in various environmental water. Estrogens in the environment mainly originate from human and animal excretions and from industrial and agricultural waste. ${ }^{1-3}$ They have been found at low concentrations in surface and groundwater, due to their poor solubility. ${ }^{4}$ EDC contamination can also be found in food, in water supplies and in consumer products - and can lead to adverse health effects, particularly with regard to reproduction and developmental growth. ${ }^{5}$ The EU has recommended monitoring these compounds in environmental 
waters because of the potential harm to aquatic species, such as alterations of sexual development. ${ }^{1,6-9}$ Traditional analytical methods are mostly employed to measure estrogens such as gas chromatography (GC), high-performance liquid chromatography (HPLC) coupled with mass spectrometry (MS) and immunoassays. ${ }^{4-9-12}$ HPLC and GC methods are typically highly automated, very sensitive and highly specific for the detection and quantification of multiple species at trace level. Although these methods provide accurate and sensitive detection, they are expensive, require highly skilled operators, present a very long turnover between sampling and results and cannot be deployed in the field. ${ }^{13}$

Estrone (E1), 17 $\beta$-estradiol (E2) and estriol (E3) are natural estrogenic hormones; while $17 \alpha$-ethinyl estradiol (EE2) is the most common synthetic estrogen. ${ }^{1,14,15} \mathrm{E} 2$ is the most potent and abundant hormone found in females. ${ }^{6}$ E1 can be found in the human body after the menopause and is less biologically active than E2. ${ }^{16} \mathrm{EE} 2$ remains longer time in the body than natural estrogens and it is used in contraceptive pills and as a post-menopausal hormone replacement. ${ }^{16} \mathrm{E} 3$ it is produced by the placenta during pregnancy and is practically insoluble in water. It is also the least potent hormone of the four, however it is most abundant during pregnancy. Estrogenic hormones can also have negative effects on physiological processes; for example, breast and endometrial cancer can occur if there is insufficient or too much estrogen in the body. ${ }^{17}$

The four estrogenic hormones share the same tetracyclic molecular structures comprising a phenolic ring (A), two cyclohexanes (B and C) and one cyclopentane (D) ring, as shown in Table 3. ${ }^{5,6}$ All the estrogens have the same phenolic group on the A-ring. The differences between the four estrogenic hormones are the substituents on the D-ring at the position $\mathrm{C}_{16}$ and $\mathrm{C}_{17}$. E1 has a carbonyl group at $\mathrm{C}_{17}, \mathrm{E} 2$ has a hydroxyl group at $\mathrm{C}_{17}, \mathrm{E} 3$ and $\mathrm{EE} 2$ have the two-hydroxyl group at $\mathrm{C}_{16}$ and $\mathrm{C}_{17}$. 
Much research has been performed to develop sensitive methods for the detection of different environmental contaminants in water. Recently, studies on the use of infrared vibrational spectroscopy shown promising performance for environmental monitoring. Of particular interest are optical sensors based on plasmonic nanostructures that have been introduced to combine high sensitivity with compact size. ${ }^{18}$ By applying an organic analyte at the metal-air interface of metamaterial structures, the characteristic molecular vibrations of the analyte can be detected and enhanced when their spectrum coincides with the plasmonic resonant wavelengths. The resultant red-shift in the plasmonic resonance can be measured for use as an optical biosensor. ${ }^{19-21}$ This plasmonic resonant coupling is known as surface enhanced infrared absorption (SEIRA) spectroscopy. An early work by Neubrech et al. in 2008 has demonstrated resonant coupling between nanorods with the deposition of a nanometre thick layer of self-assembled monolayer octadecanethiol (ODT). The molecular signals of the ODT were strongly enhanced when coupled with the plasmonic resonant behaviour. ${ }^{22}$ Later, detection of the same ODT molecules with split-ring resonators has been demonstrated by Cubukcu et al. and Wu et al. ${ }^{23,24}$ This technique has also proved effective on several types of molecular vibrations in both proteins and non-biological, organic thin-films - and for doping of metal oxides. ${ }^{25-29}$

Here, we present the fabrication and characterization of plasmonic metamaterial nanostructure arrays based on asymmetric split H-shape (ASH) structures on a zinc selenide (ZnSe) substrate that have been designed and optimized to produce plasmonic resonances that match the molecular vibrations of E1, E2, E3 and EE2. A ZnSe substrate was chosen because of its high refractive index and large transparency window that enables detection over a broad wavelength range - from $600 \mathrm{~nm}$ to $21 \mu \mathrm{m}$. Finite-difference time-domain simulations with Lumerical were carried out to design a multiband molecular sensor for the detection of the estrogenic hormones in the mid-infrared wavelength range between $2 \mu \mathrm{m}$ and $8 \mu \mathrm{m}$. Two geometries of $\mathrm{ASH}$ resonators, labelled as $\mathrm{ASH}_{1}$ and $\mathrm{ASH}_{2}$, were selected, 
fabricated and tested. The resonances measured at normal incidence using a microscopecoupled Fourier Transform Infrared (FTIR) spectrometer showed that the distinct plasmonic resonances match closely with the six molecular bond vibration resonances (for $\mathrm{O}-\mathrm{H}, \mathrm{C}-\mathrm{H}$, $\mathrm{C}=\mathrm{O}, \mathrm{C}=\mathrm{C}, \mathrm{C} \equiv \mathrm{C}-\mathrm{H}$ and $\mathrm{C}-\mathrm{C}$ bonds - see Table 1) typical of estrogens. Additionally, we show that in a mixture of two estrogens the contribution of each estrogen could be separated and quantified.

\section{Results and discussion}

\section{Chemical characterisation of the estrogenic hormones}

The FTIR spectra of the estrogenic hormones were recorded over the broadband range from $1.25 \mu \mathrm{m}$ to $16.67 \mu \mathrm{m}\left(8000-600 \mathrm{~cm}^{-1}\right) .{ }^{30}$ Between $4.2 \mu \mathrm{m}$ and $4.3 \mu \mathrm{m}\left(2380\right.$ and $\left.2300 \mathrm{~cm}^{-1}\right)$, all spectra displayed two peaks from the asymmetric stretching modes of atmospheric $\mathrm{CO}_{2}$ - while the intramolecular stretching vibrations from atmospheric water vapour were visible in the region between $2.50 \mu \mathrm{m}$ and $2.85 \mu \mathrm{m}\left(4000\right.$ and $\left.3508 \mathrm{~cm}^{-1}\right)$. On the presented figures the $\mathrm{CO}_{2}$ peaks have been removed. E1, E2, E3 and EE2 absorb significantly in the infrared radiation spectrum between $2.98 \mu \mathrm{m}$ and $7.8 \mu \mathrm{m}\left(3355\right.$ to $\left.1281 \mathrm{~cm}^{-1}\right)$ as shown in the spectra in Figure 1. The circular black dashed lines indicate molecular vibrational stretching (v) modes for the $\mathrm{O}-\mathrm{H}, \mathrm{C}-\mathrm{H}, \mathrm{C}=\mathrm{O}, \mathrm{C}=\mathrm{C}, \mathrm{C} \equiv \mathrm{C}-\mathrm{H}$ and $\mathrm{C}-\mathrm{C}$ (aromatic) and $\mathrm{C}-\mathrm{O}-\mathrm{H}$ bonds, respectively. Some features are present in all four estrogens as they only differ by a few atoms. The phenolic $\mathrm{O}-\mathrm{H}$ bond absorbs at wavelengths between $2.86 \mu \mathrm{m}$ and $3.10 \mu \mathrm{m}$ (3496 and $3225 \mathrm{~cm}^{-1}$ ) in the broadband. The strong and sharp peaks featured around 3.40 $\mu \mathrm{m}$ and $3.43 \mu \mathrm{m}\left(2941\right.$ to $\left.2915 \mathrm{~cm}^{-1}\right)$ and $3.49 \mu \mathrm{m}$ to $3.51 \mu \mathrm{m}\left(2865\right.$ to $\left.2849 \mathrm{~cm}^{-1}\right)$ were present in all four spectra due to the absorption by the $\mathrm{C}-\mathrm{H}$ bonds in the $\mathrm{CH}_{2}$ and $\mathrm{CH}_{3}$ groups in the molecule. Most of the $\mathrm{C}-\mathrm{H}$ bonds in the analytes showed strong absorption bands for stretching vibrations. The peak corresponding to carbon-to-carbon double bonds stretching $\left(\mathrm{v}_{\mathrm{C}=\mathrm{C}}\right)$ appears around $6.3 \mu \mathrm{m}\left(1587 \mathrm{~cm}^{-1}\right)$, while peaks for the single C-C bond 
in an aromatic ring stretching vibration have wavelengths between $6.6 \mu \mathrm{m}$ and $6.8 \mu \mathrm{m}(1515$ to $\left.1471 \mathrm{~cm}^{-1}\right)$. Individual estrogenic compounds also present some unique features. The $\mathrm{C} \equiv \mathrm{C}$ stretching bond of EE2 absorbs at $3.03 \mu \mathrm{m}\left(3300 \mathrm{~cm}^{-1}\right)$ and the stretching $\mathrm{C}=\mathrm{O}$ bond of $\mathrm{E} 1 \mathrm{absorbs}$ in the range between $5.79 \mu \mathrm{m}$ and $5.85 \mu \mathrm{m}\left(1727\right.$ and $\left.1709 \mathrm{~cm}^{-1}\right)$ (Table 1). The estrogenic hormone peak positions and peak shapes are in good agreement with literature and infrared spectrum in the NIST Chemistry WebBook. ${ }^{31-34}$ Theoretically, the four estrogens could be distinguished by using their unique FTIR spectral fingerprint.

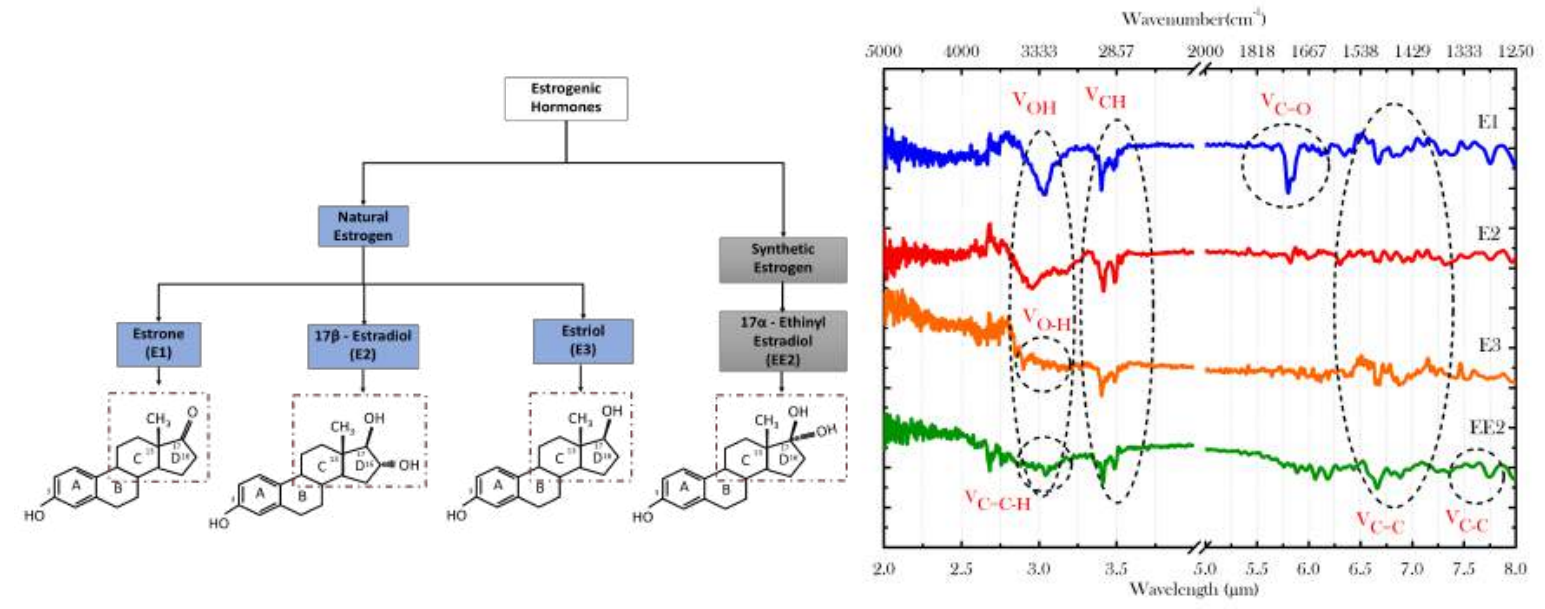

Figure 1: Illustration of (a) Estrone (b) 17 $\beta$-Estradiol (c) Estriol and (d) $17 \alpha$-Ethinyl Estradiol chemical structures showing the common regions in functional groups in the square red dashed lines. The magnified transmittance measurement results of the $10 \mu \mathrm{g}$ estrogenic hormones deposited on the plain ZnSe substrate between $2.00 \mu \mathrm{m}$ to $8.00 \mu \mathrm{m}$. The signals were recorded with $380 \times 380$ $\mu \mathrm{m}^{2}$ sized area. To aid clarity the plots are displaced in the vertical direction. 
Table 1: The summary of molecular vibrational peaks and absorption features extracted from the estrogenic hormones deposited on plain ZnSe substrate in the mid-IR wavelength between $2.00 \mu \mathrm{m}$ to $8.00 \mu \mathrm{m}$.

\begin{tabular}{|c|c|c|c|c|}
\hline $\begin{array}{c}\text { Molecular } \\
\text { Bonds }\end{array}$ & $\begin{array}{c}\text { E1 } \\
(\mu \mathrm{m})\end{array}$ & $\begin{array}{c}\text { E2 } \\
(\mu \mathrm{m})\end{array}$ & $\begin{array}{c}\text { E3 } \\
(\mu \mathrm{m})\end{array}$ & $\begin{array}{c}\text { EE2 } \\
(\mu \mathrm{m})\end{array}$ \\
\hline \hline $\mathrm{C}_{17}-\mathbf{O}-\mathbf{H}$ & & 2.96 & 2.90 & 2.92 \\
\hline $\mathrm{C}_{16}-\mathbf{O}-\mathbf{H}$ & 3.05 & & 3.05 & \\
\hline $\mathbf{C} \equiv \mathbf{C H}$ & & & & 3.03 \\
\hline $\mathbf{C}-\mathbf{H}$ & 3.40 & 3.41 & 3.41 & 3.41 \\
& 3.49 & 3.48 & 3.48 & 3.48 \\
\hline $\mathbf{C}=\mathbf{O}$ & 5.79 & & & \\
\hline $\mathbf{C}=\mathbf{C}$ & 6.85 & & & \\
\hline $\mathbf{C}-\mathbf{C}$ & 6.67 & 6.67 & 6.67 & 6.30 \\
$($ aromatic $)$ & 6.80 & 6.80 & 6.80 & 6.67 \\
\hline $\mathbf{C}_{\mathbf{1 7}}-\mathbf{O}-\mathrm{H}$ & & 7.76 & 7.76 & \\
\hline
\end{tabular}

Samples of the estrogens deposited on plain ZnSe substrates were characterized by atomic force microscopy (AFM) to evaluate their thickness and roughness (see Figure A1). The thicknesses of the solid estrogen deposits, range from 50 to 600 nm; with E1 giving an average thickness of $400 \mathrm{~nm} \pm 10 \mathrm{~nm}, \mathrm{E} 2$ is $100 \mathrm{~nm} \pm 2 \mathrm{~nm}, \mathrm{E} 3$ is $600 \mathrm{~nm} \pm 10 \mathrm{~nm}$ and EE2 is $50 \mathrm{~nm} \pm 1 \mathrm{~nm}$. The AFM profiles showed large variations in the roughness of the deposited estogens. To understand these variations, microscopic images of the samples were produced with 5x and 100x magnification (Figure 2). E2 and EE2 crystallised in small homogenous spheres, while E3 formed bigger aggregates of rod-shaped crystals. The crystallization of E1 was very heterogenous, presenting large clusters of crystals. 


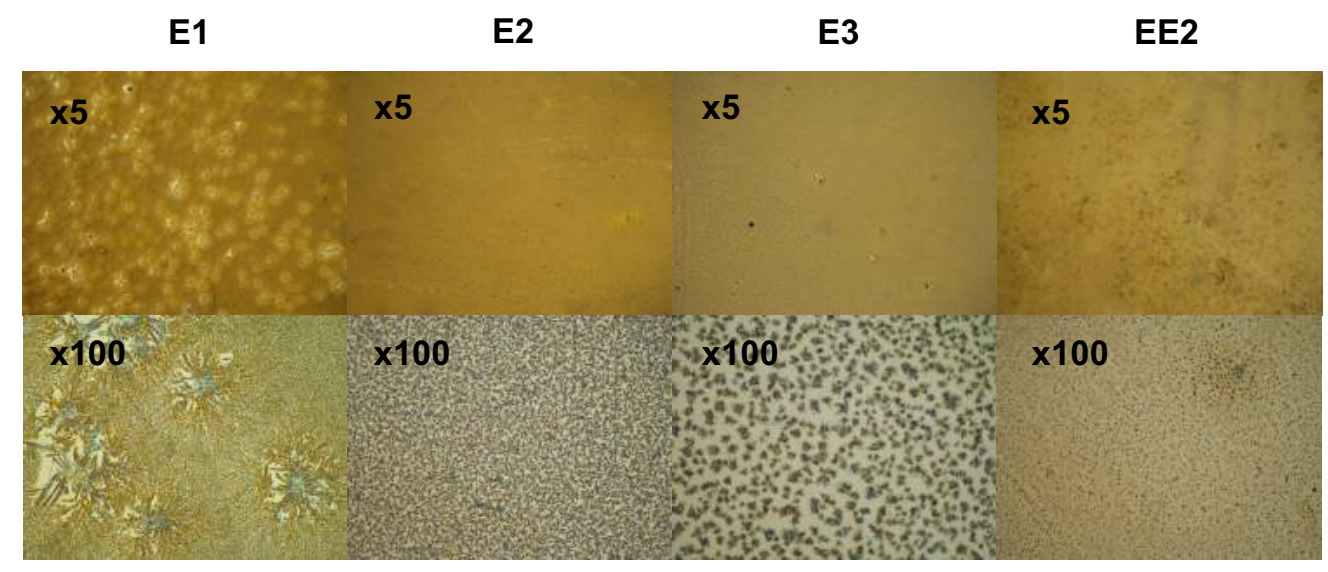

Figure 2: Microscope images of estrogen on bare ZnSe substrates, with 5x and 100x magnification

\section{Matching the molecular bonds of estrogens with ASH resonance}

The fabricated ASHs comprise two arms of different lengths, which produced two plasmonic resonances. Their thickness (t) and width (w) were $100 \mathrm{~nm}$ and they presented a constant gap (g) of $50 \mathrm{~nm}$ between the cross-bar dipoles (Figure 3(a)). In order to optimise their sensing capability, the arm lengths of the ASHs were tuned so their resonances matched or overlapped with the wavelengths of the identified molecular vibrations of the estrogens. To be able to cover the plasmonic resonance in the mid IR wavelength range between 2 and 8 $\mu \mathrm{m}, \mathrm{ASH}$ structures with two sets of different dimensions were designed; $\mathrm{ASH}_{1}$, the smaller structure, with arm lengths between $450 \mathrm{~nm}$ and $800 \mathrm{~nm}$, and $\mathrm{ASH}_{2}$, the larger structure, with arm lengths between $1.2 \mu \mathrm{m}$ and $1.6 \mu \mathrm{m}$. The lateral spacing between the ASHs along the $\mathrm{X}$ and $\mathrm{Y}$-axes was $1.1 \mu \mathrm{m}$ for $\mathrm{ASH}_{1}$ and $2.2 \mu \mathrm{m}$ for $\mathrm{ASH}_{2}$ and was fixed for all array sizes of $400 \times 400 \mu \mathrm{m}^{2}$. Scanning electron micrograph (SEM) images of a single unit and of arrays are shown in Figure 3(b)(c). 

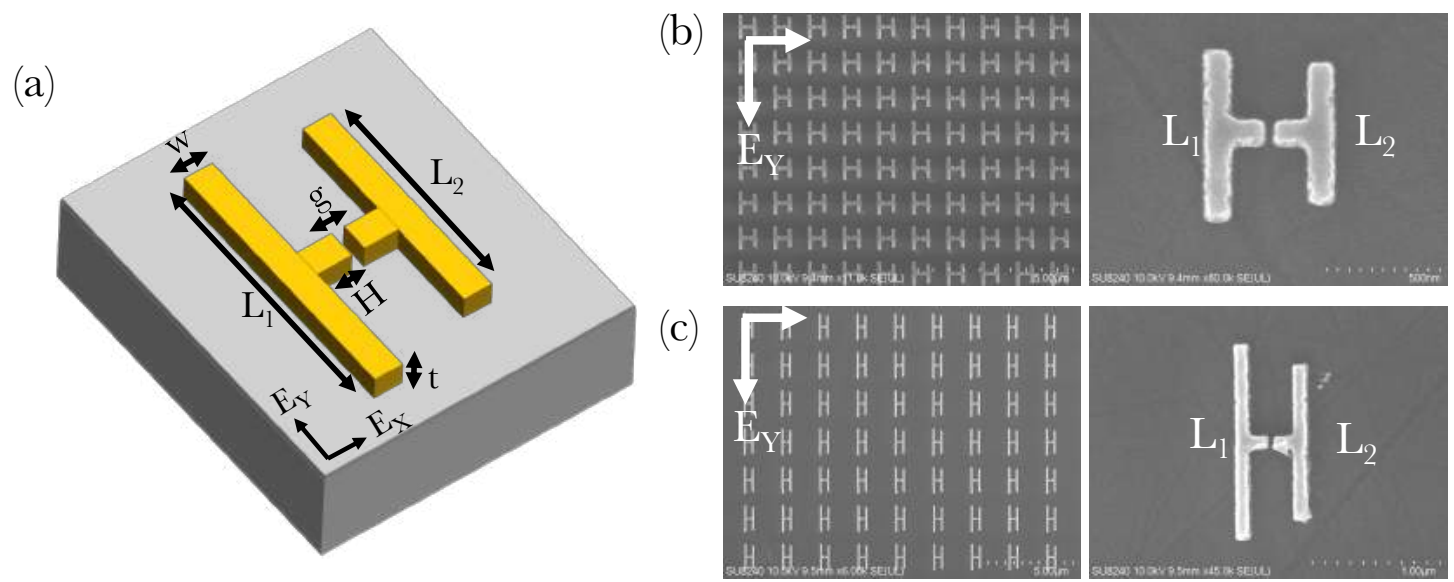

Figure 3: (a) Schematic diagrams of asymmetric split-H resonators in one-unit cells including the geometrical parameters, arm lengths $\left(\mathrm{L}_{1}\right.$ and $\left.\mathrm{L}_{2}\right)$, horizontal dipole $(\mathrm{H})$ width $(\mathrm{w})$, gap $(\mathrm{g})$ and thickness (t). The incident light polarization, $\mathrm{E}_{Y}$ and $\mathrm{E}_{X}$ are shown in the figure. Scanning electron micrograph image of an array and one-unit cell of ASH resonators with different sizes; (b) $\mathrm{ASH}_{1}$ and (c) $\mathrm{ASH}_{2}$.

The FTIR transmittance spectra were measured at normal incidence, where the incident wave is polarized along the y-axis, parallel with the vertical asymmetric arms. Reference measurements were performed on the plain ZnSe substrate to normalise the ASH measurement. The effects of varying the arm lengths can be seen in Figure 4(a)(b). The two resonances of $\mathrm{ASH}_{1}, \lambda_{1}$, corresponding to the transmittance peak of $\mathrm{L}_{2}$ and $\lambda_{3}$, to the transmittance peak of $\mathrm{L}_{1}$, were observed at wavelengths between $2.5 \mu \mathrm{m}$ and $3.5 \mu \mathrm{m}\left(4000\right.$ and $\left.2857 \mathrm{~cm}^{-1}\right)$ and the reflectance dip located between the two transmittance peaks, and denoted as $\lambda_{2}$, was between $2.8 \mu \mathrm{m}$ and $3.2 \mu \mathrm{m}$ (3571 and $3125 \mathrm{~cm}^{-1}$ ) (Figure 4(c)(d)). For $\mathrm{ASH}_{2}, \lambda_{1}$ and $\lambda_{3}$ produced transmittance resonances between $5.5 \mu \mathrm{m}$ and $7.0 \mu \mathrm{m}\left(1818\right.$ and $\left.1428 \mathrm{~cm}^{-1}\right)$ and $\lambda_{2}$ between $5.8 \mu \mathrm{m}$ to $6.3 \mu \mathrm{m}\left(1724\right.$ and $\left.1587 \mathrm{~cm}^{-1}\right)$. When $\mathrm{L}_{2}$ was increased the peak positions of $\lambda_{2}$ and $\lambda_{3}$ were red-shifted. The distinct plasmonic resonance peak positions varied linearly, depending directly on the arm length. The experimental transmittance peak spectrum was in good agreement with the simulation results shown in Figure 4(c)(d). 


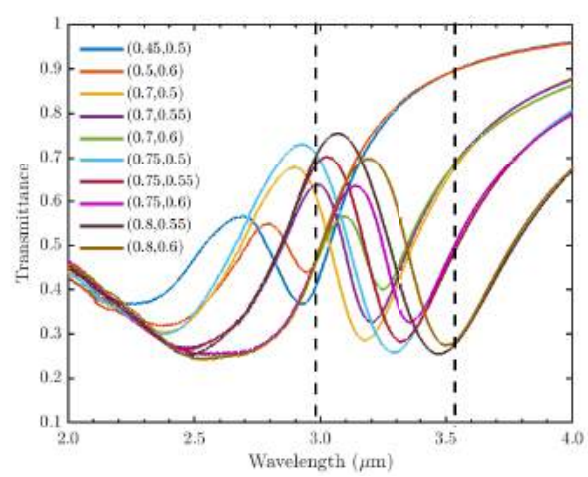

(a)

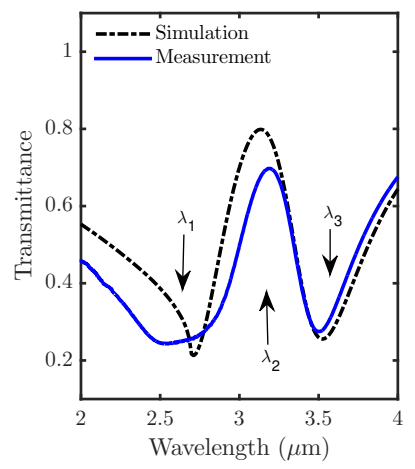

(c)

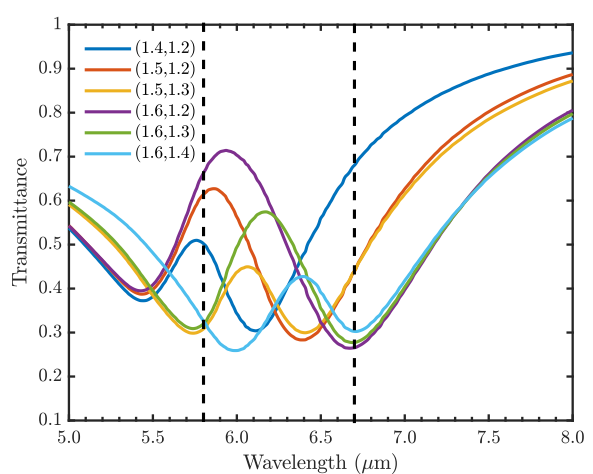

(b)

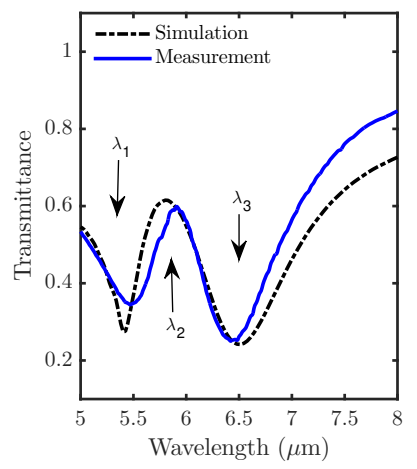

(d)

Figure 4: Experimental results of tuning the arm-length of (a) $\mathrm{ASH}_{1}$ to produce resonance at 2 to $4 \mu \mathrm{m}$ and (b) $\mathrm{ASH}_{2}$ at 5 to $8 \mu \mathrm{m}$. The position of the targeted molecular bonds are shown with the black dashed lines. Simulated and measurement spectra of (c) $\mathrm{ASH}_{1}$ and (d) $\mathrm{ASH}_{2}$. The black dashed line is the simulated results obtained by Lumerical FDTD and the blue line is the measurement results using for corresponding $\mathrm{ASH}_{1}(800 \mathrm{~nm}, 600 \mathrm{~nm})$ and $\mathrm{ASH}_{2}(1.5 \mu \mathrm{m}, 1.2 \mu \mathrm{m})$.

To illustrate the enhancing power of matching the resonance of molecular bonds, the FTIR spectra of $\mathrm{ASH}_{1}$ with different sizes of $\mathrm{L}_{1} \mathrm{~s}$ are presented in Figure 5. Initially, the effect of the deposition of estrogen on the selected nanostructures was investigated by measuring the IR spectra after E2 deposition. The plasmonic resonances of the ASHs were distorted as a result of E2 deposition and a substantial red-shift was produced, compared with the resonances of the bare ASH. This change is due to the higher refractive index of E2 $(\mathrm{n} \approx 1.55),{ }^{29,35}$ as compared with the refractive index of air $(\mathrm{n}=1)$. When deposited on the nanostructures, E2 crystallized on top of the resonators, giving a thickness of approximately $100 \mathrm{~nm} \pm 2 \mathrm{~nm}$ (Figure 5). The magnified spectrum (Figure 5(d)) over the wavelength range from 3.35 to $3.55 \mu \mathrm{m}$ shows the different enhanced signal strengths of the $\mathrm{C}-\mathrm{H}$ bonds. 
The strongest signal enhancement was observed when the coupling between the plasmonic resonance and the molecular vibrational spectrum was closest. For the $\mathrm{C}-\mathrm{H}$ bond vibration at $3.41 \mu \mathrm{m}$, the signal on bare ZnSe had a $0.01 \%$ transmittance, while it reached $5 \%$ when matched with the reflection $\operatorname{dip}\left(\lambda_{2}\right)$ of the nanostructures for $\mathrm{L}_{1}$ of $800 \mathrm{~nm}$. When $\mathrm{L}_{1}$ $=750 \mathrm{~nm}$, the bond vibration peak matched with the transmittance peak $\left(\lambda_{3}\right)$ and the peak intensity was reduced to $4 \%$ and at $\mathrm{L}_{1}=700 \mathrm{~nm}$ the bond vibration peak appeared on the slope of $\lambda_{3}$ and was further reduced to $2 \%$. The line width of the plasmonic resonance was also modified by coupling effects. The same amount of E2 was deposited in all cases and the maximum enhancement factor was hence 500. $\mathrm{ASH}_{1}$, with $\mathrm{L}_{1}=800 \mathrm{~nm}$ and $\mathrm{L}_{2}=600 \mathrm{~nm}$ presented the greatest enhancement for the $\mathrm{C}-\mathrm{H}$ bond peaks as indicated in Figure 5(d)(e), while for $\mathrm{ASH}_{2}$ with $\mathrm{L}_{1}=1.5 \mu \mathrm{m}$ and $\mathrm{L}_{2}=1.2 \mu \mathrm{m}$, the $\mathrm{C}=\mathrm{C}$ and $\mathrm{C}-\mathrm{C}$ (aromatic) stretching vibration peaks were matched with the reflection dips and transmittance peak of $\mathrm{ASH}_{2}$. The stretching vibration for $\mathrm{C}_{17}-\mathbf{O}-\mathbf{H}$ and $\mathbf{C}_{\mathbf{1 7}}-\mathbf{O}-\mathrm{H}$ were not enhanced significantly by the device present in E2, E3 and EE2 (Table 1). 


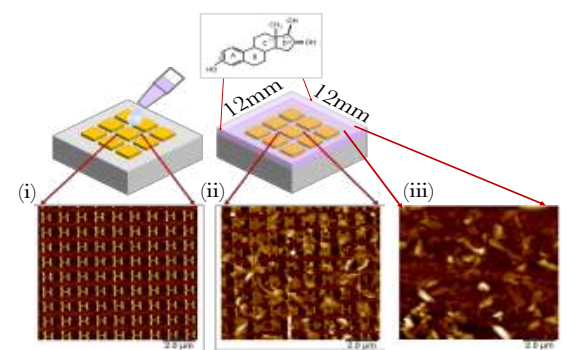

(a)

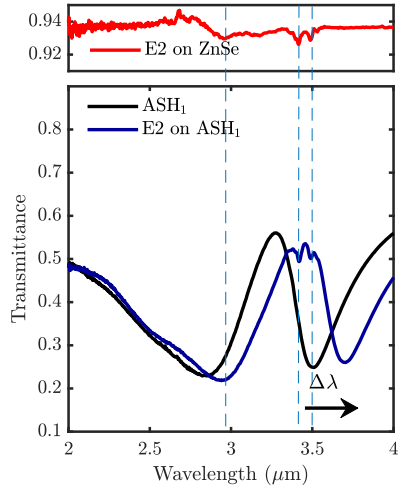

(b)
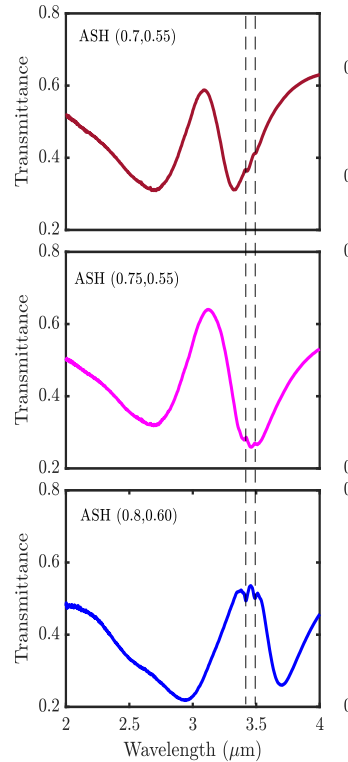

(d)

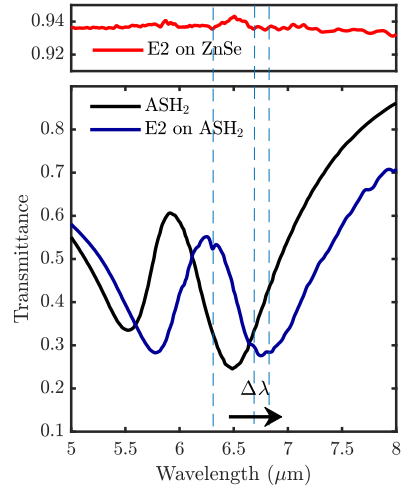

(c)
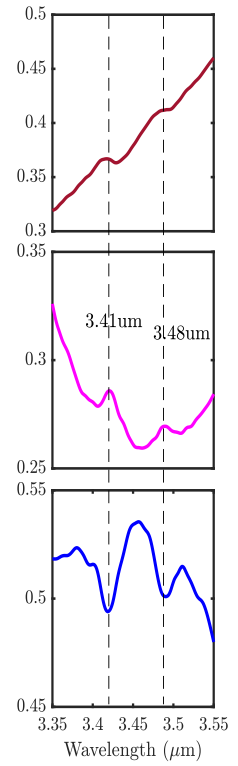

Figure 5: (a) AFM images show $1 \mathrm{mg} / \mathrm{ml}$ concentration of E2 in EtOH (i) before and (ii) after deposition on the ASH arrays (iii) on the ZnSe substrate alone over an area of $10 \mathrm{x} 10 \mu \mathrm{m}^{2}$. The E2 was crystallized on top of the sample. The figures showed the shift in the position of the transmittance resonance from (b) $\mathrm{ASH}_{1}$ (c) $\mathrm{ASH}_{2}$ sample before (black line) and after (blue line) the deposition of $1 \mathrm{mg} / \mathrm{ml}$ concentration of E2. The red line in both plots shows the deposition of E2 on the bare ZnSe substrate. The dashed blue line indicates the molecular bond vibration matched with the resonance shifted. (d) The transmittance spectra of three selected sizes of ASH as indicated covered with a thin layer of $\mathrm{E} 2$. The black dashed line refers to the $\mathrm{C}-\mathrm{H}$ bond resonance at 3.41 $\mu \mathrm{m}$ and $3.48 \mu \mathrm{m}$. The plot on the right is magnified to show the molecular vibration of the $\mathrm{C}-\mathrm{H}$ bond. 
For $\mathrm{ASH}_{1}$, the resonances shifted after E2 deposition from $3.27 \mu \mathrm{m}$ to $3.47 \mu \mathrm{m}$ and 3.50 $\mu \mathrm{m}$ to $3.71 \mu \mathrm{m}$ and for $\mathrm{ASH}_{2}$ from $5.92 \mu \mathrm{m}$ to $6.27 \mu \mathrm{m}$ and $6.49 \mu \mathrm{m}$ to $6.79 \mu \mathrm{m}$, i.e a $200 \mathrm{~nm}$ shift for $\mathrm{ASH}_{1}$ and around $300 \mathrm{~nm}$ for $\mathrm{ASH}_{2}$. All the resonance shift data are presented in Table 2. The spectral sensitivity, S (in units of nm/RIU) of the nanostructures was calculated using the ratio between the changes in the resonance peak positions $(\Delta \lambda)$ and the changes in the refractive index $(\Delta \mathrm{n})$. The sensitivity of $\mathrm{ASH}_{1}$ and $\mathrm{ASH}_{2}$ was $363 \mathrm{~nm} / \mathrm{RIU}$ and 636 $\mathrm{nm} / \mathrm{RIU}$, respectively. Figure of merit (FOM) values were also calculated using the formula $\mathrm{FOM}=\mathrm{S} / \mathrm{FWHM}$, where FWHM is the full-width half-maximum and has units of nm. The maximum value of the $\mathrm{FOM}$ for $\mathrm{ASH}_{1}$ was $\mathrm{FOM}_{1}=0.9 \mathrm{RIU}$ and $\mathrm{ASH}_{2}$ was $\mathrm{FOM}_{2}=1.3 \mathrm{RIU}$.

Table 2: Summary of the initial position of $\mathrm{ASH}_{1}$ and $\mathrm{ASH}_{2}$ and resonance shifted after deposition of $\mathrm{E} 2$ on the nanostructures. The sensitivity was calculated by spectral shift to the refractive index change. The value of refractive index change is $\Delta \mathrm{n} \approx 1.55$.

\begin{tabular}{|c|c|c|c|c|c|c|c|c|c|}
\hline \multicolumn{5}{|c|}{$\mathrm{ASH}_{1}$} & \multicolumn{5}{c|}{$\mathrm{ASH}_{2}$} \\
\hline & $\begin{array}{c}\text { Initial } \\
(\mu \mathrm{m})\end{array}$ & $\begin{array}{c}\text { Shift } \\
(\mu \mathrm{m})\end{array}$ & $\begin{array}{c}\lambda \\
(\mu \mathrm{m})\end{array}$ & $\mathbf{S}$ & $\begin{array}{c}\text { Initial } \\
(\mu \mathrm{m})\end{array}$ & $\begin{array}{c}\text { Shift } \\
(\mu \mathrm{m})\end{array}$ & $\begin{array}{c}\lambda \\
(\mu \mathrm{m})\end{array}$ & $\mathbf{S}$ \\
\hline$\lambda 1$ & 2.84 & 2.96 & 120 & 218 & $\lambda 1$ & 5.54 & 5.79 & 250 & 454 \\
\hline$\lambda 2$ & 3.27 & 3.47 & 200 & 363 & $\lambda 2$ & 5.92 & 6.27 & 350 & 636 \\
\hline$\lambda 3$ & 3.50 & 3.70 & 200 & 363 & $\lambda 3$ & 6.49 & 6.79 & 300 & 545 \\
\hline
\end{tabular}

The other three estrogenic hormones (E1, E3, and EE2) were also deposited on the nanostructures (Figure A2). The red shifts induced by the deposition of E1 (53 nm) and E3 $(60 \mathrm{~nm})$ on $\mathrm{ASH}_{1}$ were smaller than for E2 while it was more similar for EE2. Consequently, the vibration modes were matched by $\lambda_{3}$ rather than $\lambda_{2}$ and no strong enhancement could be observed for E1 and E3. This may be explained by our previous observation that crystallization of E2 and EE2 forms much more homogeneous layers than E1 and E3. The crystal aggregation may have been blocking the enhancement and the local refractive index is different. Similarly, for E2 the $\mathrm{O}-\mathrm{H}$ vibration bonds were not clearly resolved, even when the resonance was matched possibly because they produced a relatively broad absorption peak spectrum. The unique feature of EE2, the stretching vibration mode of the $\mathrm{C} \equiv \mathrm{C}-\mathrm{H}$ bond, did not appear on the spectrum. Smaller shifts are also observed on $\mathrm{ASH}_{2}$, leading 
to smaller enhancement for the $\mathrm{C}=\mathrm{C}$ and $\mathrm{C}-\mathrm{C}$ (aromatic) stretching vibration peaks. The unique feature of $\mathrm{E} 1$, the stretching vibration mode of the $\mathrm{C}=\mathrm{O}$ bond, was enhanced as it matched $\lambda_{1}$.

\section{Detection of a mixture of two estrogenic hormones}

The plasmonic nanostructures were coated with a thin layer of a $10 \mu \mathrm{g}$ mixture of E2 with one of the other hormones, E1, E3 or EE2, in absolute ethanol with a total estrogen concentration of $2 \mathrm{mg} / \mathrm{ml}$ (Table A2). For mixtures of E2 and E1, E2:E1 ratios were also varied (Table A3). The estrogen mixtures were deposited as described previously, on all the samples, and were left to dry overnight; the total quantity of estrogens on the device was in each case $20 \mu \mathrm{g}$ (twice as much as in the previous experiment). To detect the molecular response of the mixtures of estrogen, the transmittance spectra were measured over an area of $380 \mathrm{x}$ $380 \mu \mathrm{m}^{2}$ (Figure A3 and Figure A4).

In order to quantitatively evaluate the experimental results, baseline correction was used to extract the peak intensities for various molecular vibrations. Baseline correction was carried out using the asymmetric least squares smoothing (AsLSS) algorithm in MATLAB code, as introduced by Eilers. ${ }^{36}$ The calculations were performed by dividing the transmittance resonance of the analyte $\left(\mathrm{T}_{E S}\right)$ with the corresponding baseline $\left(\mathrm{T}_{B A S E}\right)$ - so that only the enhanced signal appears $\left(\mathrm{T}_{R E L}=\mathrm{T}_{E S} / \mathrm{T}_{B A S E}\right)$. The peak amplitude of the enhanced signal was calculated on the basis of a peak-to-peak value - and Fano-resonant line-shape was produced: when the peaks match $\lambda_{1}$ and $\lambda_{3}$ the baseline corrected spectrum will show a dip, while a positive peak will represent peak matched to $\lambda_{2}$.

Figure 6(c)(d) shows a comparison of the signals, after baseline correction, of the spectra of the mixture of E2:E1 (green line), E2:E3 (olive line) and E2:EE2 (purple line). The peak 
that appears between $2.50 \mu \mathrm{m}$ and $3.00 \mu \mathrm{m}$ is the ripple from atmospheric $\mathrm{H}_{2} \mathrm{O}$. The red shifts in the mixture E2:EE2 was similar to E2 and the enhancement of the peaks were maximum for both $\mathrm{ASH}_{1}$ and $\mathrm{ASH}_{2}$. For the mixture E2:E1, the red shifts were slightly smaller but the enhancements were still good for all peaks. The $\mathrm{v}_{\mathrm{C}=\mathrm{O}}$ fell on $\lambda_{1}$ on $\mathrm{ASH}_{2}$ at a wavelength of around $5.79 \mu \mathrm{m}$. Finally, for E2:E3, the resonance shifts were the smallest and therefore the enhancements were smaller Figure 6(b). After baseline correction, the peak intensities of $3.1 \%, 3.29 \%$ and $3.57 \%$ for the $\mathrm{C}-\mathrm{H}$ respectively can be easily identified (Figure 6(e)). The peak intensity was similar for each mixture due to the $\mathrm{C}-\mathrm{H}$ bond existing in all the estrogens. The $\mathrm{CH}_{3}$ peak intensity was much lower than the peak intensity of $\mathrm{CH}_{2}$ at $2.7 \%, 2.45 \%$ and $3.34 \%$ respectively due to the weaker signals from $\mathrm{CH}_{3}$. Comparison of the peak intensities in the various mixtures showed that by using $\mathrm{ASH}_{1}$ and $\mathrm{ASH}_{2}$, the different estrogens could be identified and their molar fractions could potentially be determined particularly for $\mathrm{E} 1$ and $\mathrm{E} 2$ has the peak of $\mathrm{C}=\mathrm{O}$, distinctive of $\mathrm{E} 1$, was enhanced (Figure $7(\mathrm{a}))$. 


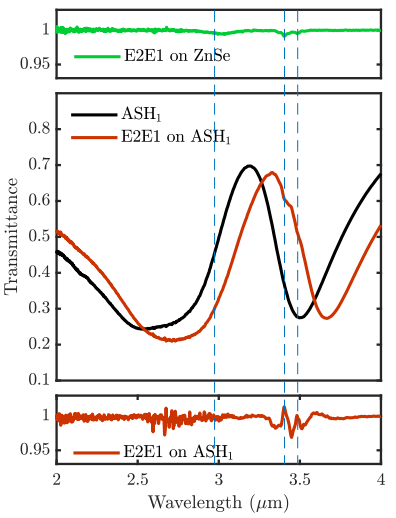

(a)

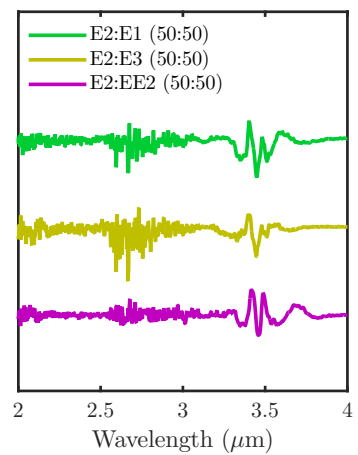

(c)

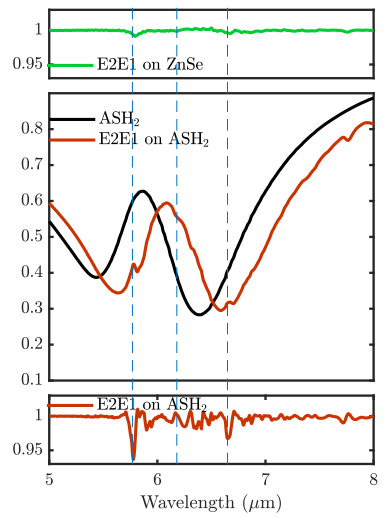

(b)

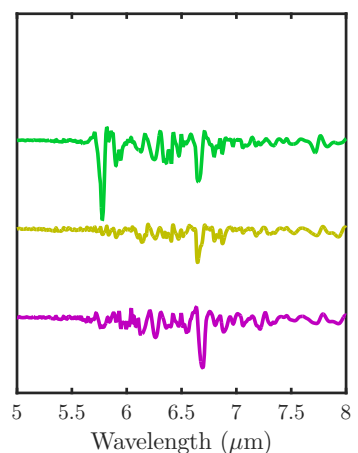

(d)

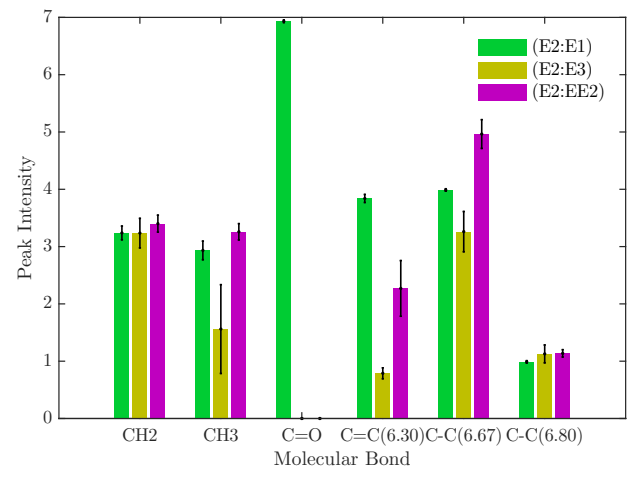

(e)

Figure 6: The upper panel: The vibrational transmittance spectrum of E2: E1 on the 1mm thickness ZnSe substrate alone measured with $380 \times 380 \mu \mathrm{m}^{2}$. Middle panel: Plots transmittance resonances of shift in position (a) $\mathrm{ASH}_{1}$ and (b) $\mathrm{ASH}_{2}$ before (black colour) and after coated (red colour) with the mixtures of $\mathrm{E} 2$ and $\mathrm{E} 1$ (50:50). The lower panel: shows the vibrational resonances after the baseline correction in the fingerprints of $\mathrm{O}-\mathrm{H}, \mathrm{C}-\mathrm{H}(\mathrm{x} 2), \mathrm{C}=\mathrm{O}$ and $\mathrm{C}=\mathrm{C}(\mathrm{x} 2)$ bonds. The position of the respective vibrational resonances are shown with the blue dashed lines. (c) $\mathrm{ASH}_{1}$ and (d) $\mathrm{ASH}_{2}$ are baseline correction spectra of the mixtures E2 with E1 (green line), E3 (olive line) and EE2 (purple line). The peak amplitude of the enhanced signal was calculated based on a peak to peak value. The peak position agrees well with the deposition on the ZnSe substrate alone. Stacked plots were used for the purpose of better visibility. (e) Determination of percentage peak intensity of each of the molecular bond resonances $\mathrm{C}-\mathrm{H}, \mathrm{C}=\mathrm{O}, \mathrm{C}=\mathrm{C}$ and $\mathrm{C}-\mathrm{C}$ in three different mixtures of E2 with E1, E3, and EE2. 
Because of the $\mathrm{v}_{\mathrm{C}=\mathrm{O}}$, the presence of $\mathrm{E} 1$ on the sensor can be confirmed, this why we chose to investigate the E2:E1 mixtures more closely. In mixtures ranging from (25:75) and $(0: 100)$ in weight, the resonances exhibited small shifts because the total molar amount of estrogen did not vary significantly. The resonance shifts for all E2:E1 mixtures were approximately 180, 210, 80, 168 and $30 \mathrm{~nm}$ following the mixtures in Table A3. The shift decreased with the increasing amount of E1, this can be related to a change of local refractive index as shown on the microscopic pictures of the deposits (Figure A5). Meantime, the resonance peak intensity for $\mathrm{v}_{\mathrm{C}=\mathrm{O}}$, increased from $6.9 \%$ to $9.7 \%$, as the ratios of $\mathrm{E} 1$ increased (Figure 7). The peak intensities of $\mathrm{v}_{\mathrm{C}=\mathrm{C}}$ and $\mathrm{v}_{\mathrm{C}-\mathrm{C}}$ (aromatic) remained nearly constant for each ratio, despite the small shifts. This was expected because the two estrogens have the same $\mathrm{C}=\mathrm{C}$ bonds. Quantitatively, the intensities of these peaks could, therefore, be used to indicate the total amount of the estrogen. It is also noteworthy that the shape of the $\mathrm{C}-\mathrm{H}$ bond resonances at $3.41 \mu \mathrm{m}$ and $3.49 \mu \mathrm{m}$ slowly change, depending on the ratios of E1 and E2. The peak of $\mathrm{C}-\mathrm{H}$ bond for $\mathrm{E} 1$ appeared at $3.40 \mu \mathrm{m}$ and $3.49 \mu \mathrm{m}$ and $\mathrm{E} 2$ is at $3.41 \mu \mathrm{m}$ and $3.48 \mu \mathrm{m}$. When the amount of E2 was reduced, the peak at $3.41 \mu \mathrm{m}$ was also reduced but the peak at $3.49 \mu \mathrm{m}$ increased - due to the increase of E1, as shown in Figure 7(b). The contribution of both types of estrogens can be quantitatively separated, as shown in Figure $7(a)$. Furthermore, measurements after deposition on three different areas of the ASH were consistent with the peak position remaining the same (Figure A6). 


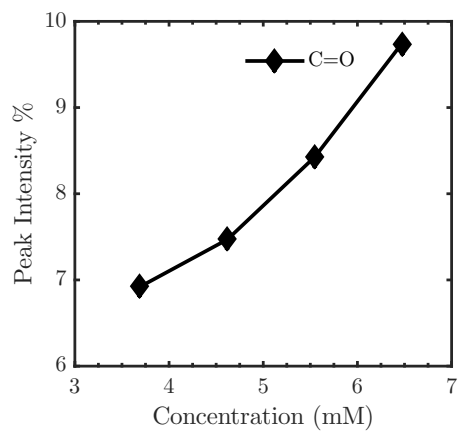

(a)

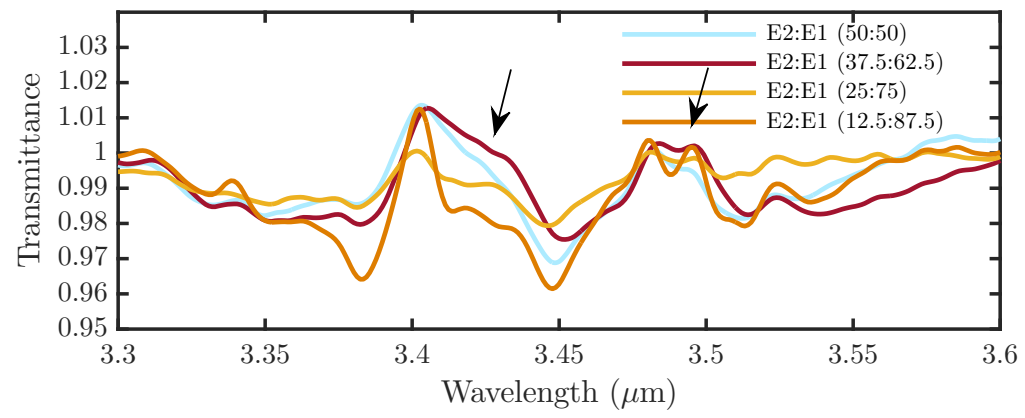

(b)

Figure 7: (a) The $\mathrm{C}=\mathrm{O}$ molecular peak intensity increases directly with the amount of $\mathrm{E} 1$ in the mixtures. (b) Fingerprint of the $\mathrm{C}-\mathrm{H}$ molecular bond signal intensities for mixtures of two estrogens E2:E1 on ASH arrays showing transmittance resonances extracted after baseline correction.

\section{Conclusion}

In conclusion, the geometry of the asymmetric split-H resonators has been tuned and utilized to enhance the molecular $\mathrm{C}-\mathrm{H}, \mathrm{C}=\mathrm{O}, \mathrm{C}=\mathrm{C}$ and $\mathrm{C}-\mathrm{C}$ bond resonances of the estrogenic hormones. The plasmonic resonance was red-shifted towards longer wavelengths with the deposition of organic materials on the nanostructures. From these observations, the molecular bond resonances are typically five hundred times larger, are easily visible and enable differentiation of different estrogens, as compared with those deposited on bare substrates. The use of plasmonic resonance coupling techniques enables identification of the common $(\mathrm{O}-\mathrm{H}, \mathrm{C}-\mathrm{H}, \mathrm{C}=\mathrm{C}$ and $\mathrm{C}-\mathrm{C})$ and different $(\mathrm{C}=\mathrm{O})$ molecular bond resonances for the two estrogen molecules, in the mid-infrared wavelength range from 2 to $8 \mu \mathrm{m}$. The ASH nanostructures can be flexibly designed over this broad wavelength range - and can be tuned to enhance the differences between the different estrogens and aid quantitative detection. 


\section{Material and Method}

\section{Chemicals and Reagents}

Estrone (E1) (99\% purity) was purchased in powder form from Acros Organic, and 17 $\beta$ Estradiol (E2) (98\% purity), Estriol (E3) (98\% purity), and 17 $\alpha$-Ethinyl Estradiol (EE2) (98\% purity) and absolute ethanol (EtOH) $(\geq 99.8 \%$ purity) were purchased from Sigma Aldrich.

\section{Gold Nanostructure Fabrication}

The gold nanostructures were fabricated using electron beam lithography (EBL) on a ZnSe

substrate from Crystran Ltd. ${ }^{37,38}$ The substrates were cleaned in an ultrasonic bath and a bilayer of PMMA positive resists was spun on top of the substrate, with a thickness of 400 nm. A thin layer of aluminium deposited over the PMMA bilayer resist acted as a charge dissipation layer to minimise charging effects during EBL patterning. After the patterning, the samples were developed with IPA:RO water (ratio 7:3). A $10 \mathrm{~nm}$ thick film of titanium, used as an adhesion layer, and $100 \mathrm{~nm}$ of gold were deposited - followed by the lift-off process in warm acetone. The pattern was written over a square array with an area of approximately $400 \times 400 \mu \mathrm{m}$. Oxygen plasma was used to remove residues of the resists on the surface before metallisation and after lift-off.

\section{FTIR Measurement}

Fourier Transform Infra-red (FTIR) transmittance spectra of gold nanostructure arrays were measured in normal incidence using a Bruker Vertex 70 spectrometer coupled to a Nicolet Continuum Hyperion microscope - with a Cassegrain objective $(15 \times, \mathrm{NA}=0.4)$ and a $\mathrm{KBr}$ beam-splitter, over the range from 8000 to $400 \mathrm{~cm}^{-1}(1.25 \mu \mathrm{m}$ to $16.67 \mu \mathrm{m})$. A liquid nitrogen-cooled mercury-cadmium-telluride (MCT) detector was used to measure the interferogram signal, which was converted into the spectrum. The IR spectra were collected over 
the same area for all arrays, with aperture sizes of $380 \times 380 \mu \mathrm{m}^{2}$. The FTIR beam was polarized using a ZnSe IR polarizer inserted into the beam path in front of the sample. All the measured spectra were normalized to the transmittance of a plain ZnSe substrate. The interferometer was maintained under vacuum and the microscope was constantly purged with nitrogen gas to eliminate the influence of water and $\mathrm{CO}_{2}$ on the spectra.

\section{FDTD Simulations}

The structures were modelled with gold on top of the ZnSe substrate and using data from Palik $^{39}$ for the complex refractive index of gold. The ZnSe substrate refractive index of $n$ $\approx 2.43$ was taken from Crystran Ltd material data sheets. ${ }^{37}$ The simulations were carried out using Lumerical finite-difference time-domain (FDTD) simulation software. ${ }^{40}$ The simulations used periodic boundary conditions along the $\mathrm{X}$ and $\mathrm{Y}$-axes, with equal periodicity, to simulate an infinite array in both directions. A perfectly-matched layer (PML) was used for the z-axis, with a wavelength range between $2 \mu \mathrm{m}$ and $8 \mu \mathrm{m}$. A plane wave source and power monitors were used to obtain the reflectance and transmittance simulation spectra.

\section{Estrogenic hormone preparation}

All the stock solutions for E1, E2, E3, and EE2 were prepared in EtOH with a concentration of $1 \mathrm{mg} / \mathrm{ml}$ and formed clear solutions after sonication for five minutes. $10 \mu \mathrm{l}$ of the solution was deposited on a ZnSe substrate and allowed to evaporate overnight in order for the estrogen to solidify on top of the substrate. ${ }^{29}$ The solutions for the mixture of two estrogens were prepared with $4 \mathrm{mg}$ of each powder in $4 \mathrm{ml}$ of EtOH, giving a total concentration of 2 $\mathrm{mg} / \mathrm{ml}$ estrogens with a 50:50 (w:w) ratio or $1+1 \mathrm{mg} / \mathrm{ml}$. Then, five different ratios (w:w) of E2 to E1 were prepared - 50:50, 37.5:62.5, 25:75, 12.5:87.5, and 0:100, corresponding to 1 $+1 \mathrm{mg} / \mathrm{ml}, 0.75+1.25 \mathrm{mg} / \mathrm{ml}, 0.5+1.5 \mathrm{mg} / \mathrm{ml}, 0.25+1.75 \mathrm{mg} / \mathrm{ml}$ and $0+2 \mathrm{mg} / \mathrm{ml}$. The

deposition was carried out at room temperature, in a fume-cabinet. Between experiments, the solutions were kept in freezer at a temperature of $-20^{\circ} \mathrm{C}$. 


\section{Acknowledgement}

IFMAN gratefully acknowledges funding by the Malaysian Government, through Majlis Amanah Rakyat (MARA) Malaysia. We also acknowledge the staff and facilities of the James Watt Nanofabrication Centre (JWNC) at the University of Glasgow for the provision of device fabrication facilities - and the environmental biotechnology laboratory for the preparation of organic materials. 


\section{Appendix}

Table A1: Illustration of (a) Estrone (b) $17 \beta$-Estradiol (c) Estriol and (d) $17 \alpha$-Ethinyl Estradiol chemical structures showing the common regions and in functional groups.

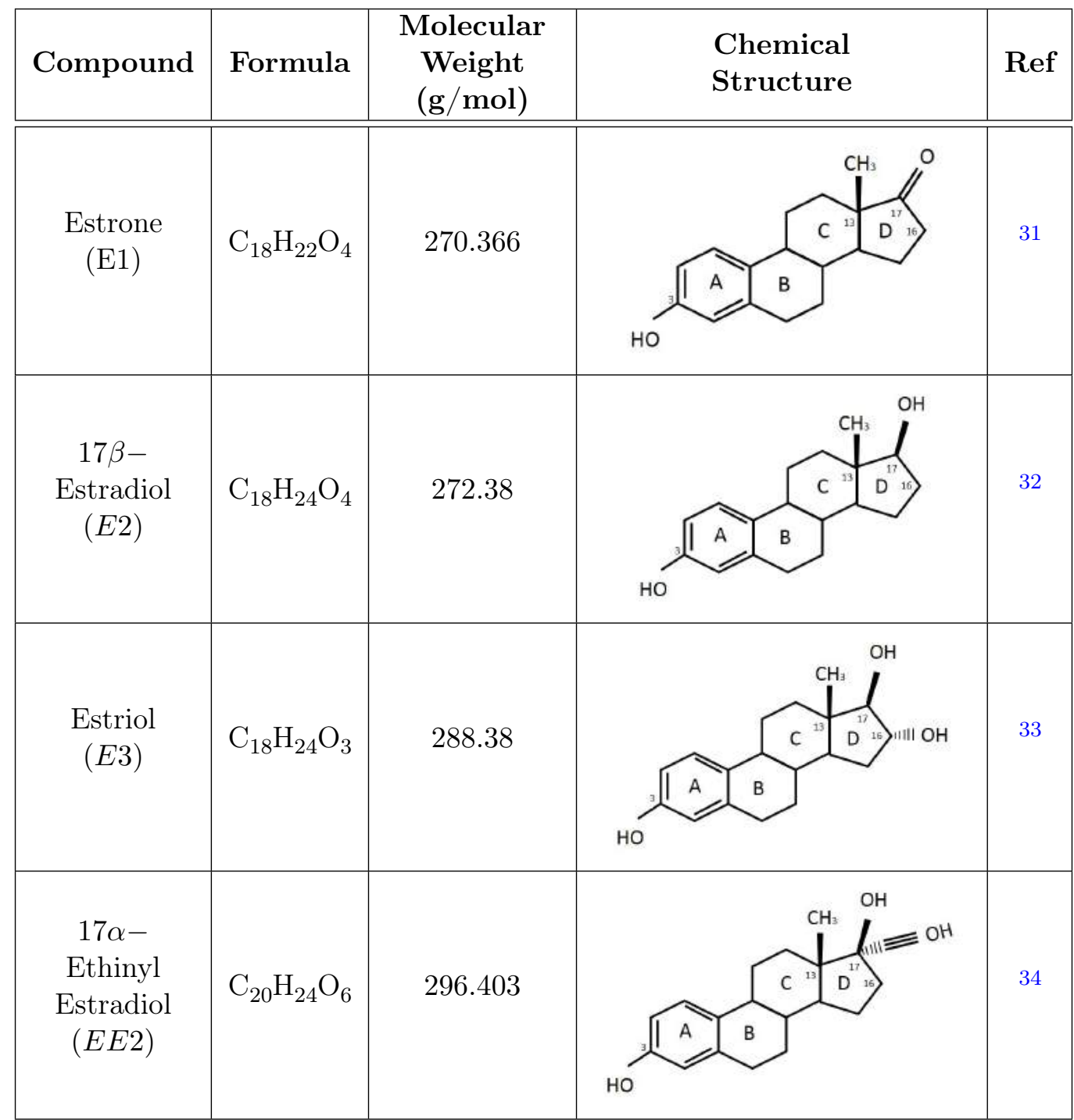




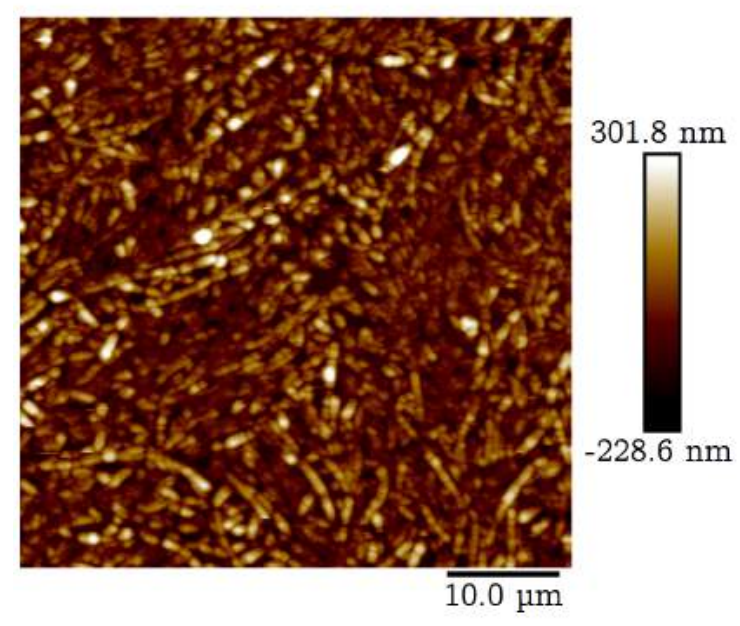

(a) E1

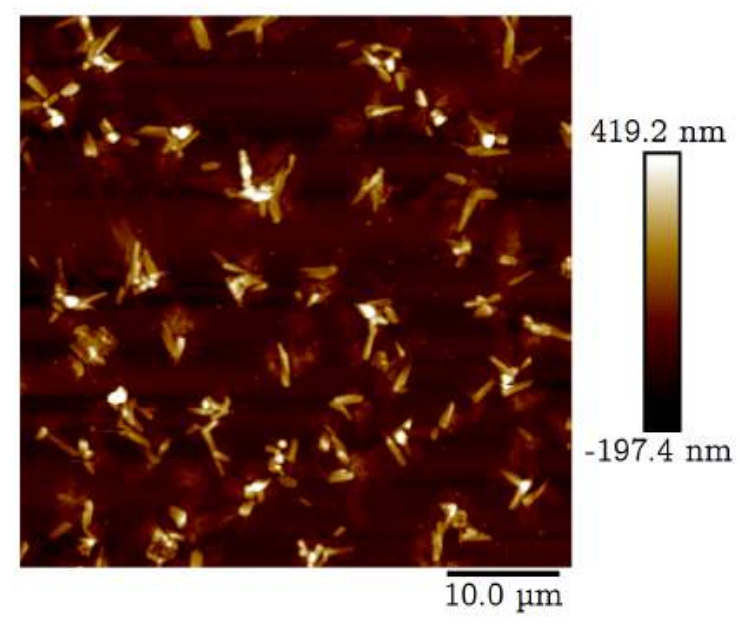

(c) E3

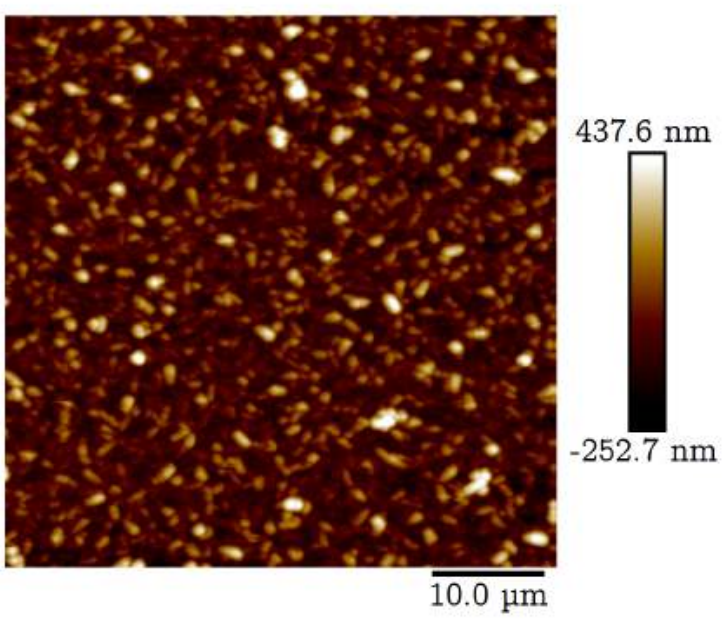

(b) E2

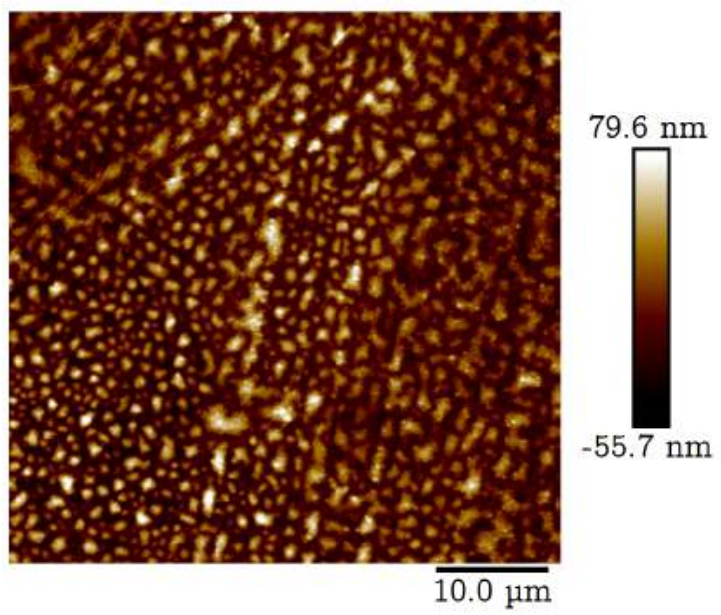

(d) EE2

Figure A1: AFM images of (a) Estrone (E1) (b) 17 $\beta$-Estradiol (E2) (c) Estriol (E3) (d) $17 \alpha$-Ethinyl Estradiol with $1 \mathrm{mg} / \mathrm{ml}$ solution concentration deposited on the ZnSe substrate. The images were obtained using ScanAsyst mode with the scale bar $10 \mu \mathrm{m}$ 


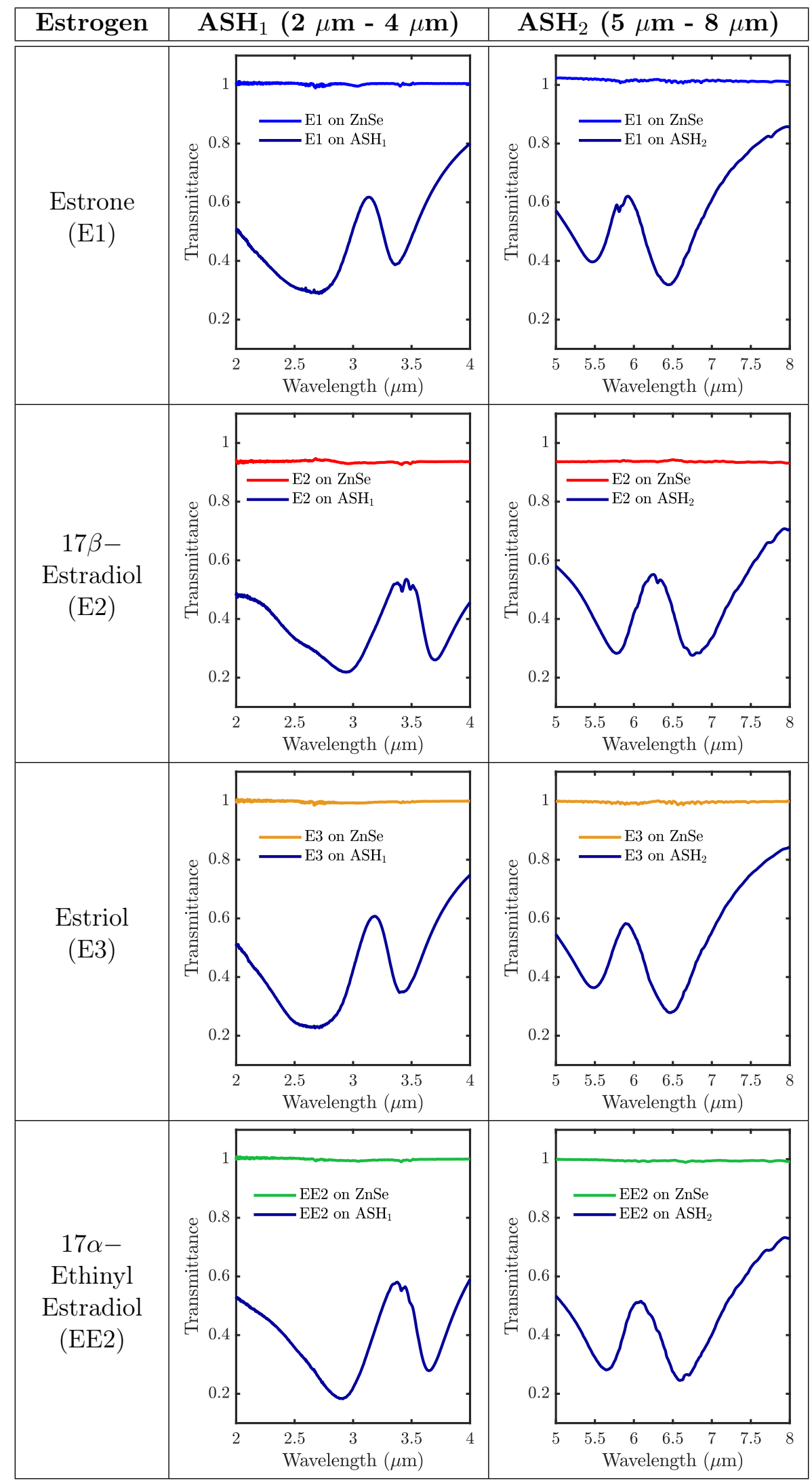

Figure A2: Plot of the transmittance resonance matching the molecular bonds of (a) Estrone (b) $17 \beta$-Estradiol (c) Estriol and (d) $17 \alpha$-Ethinyl with the plasmonic resonance. 
Table A2: Compositions of E2 - E1 mixtures with different ratios, diluted in absolute ethanol and having the same total concentration of $2 \mathrm{mg} / \mathrm{ml}$.

\begin{tabular}{|c|c|c|c|c|c|c|c|}
\hline Mix & $\begin{array}{c}\text { E2+Ex } \\
(\mathrm{mg})\end{array}$ & $\begin{array}{c}\text { EtOH } \\
(\mathrm{ml})\end{array}$ & Ratio & $\begin{array}{c}\text { E2 } \\
(\mathrm{g} / \mathrm{l})\end{array}$ & $\begin{array}{c}\text { Ex } \\
(\mathrm{g} / \mathrm{l})\end{array}$ & $\begin{array}{c}\text { E2 } \\
(\mathrm{mM})\end{array}$ & $\begin{array}{c}\text { Ex } \\
(\mathrm{mM})\end{array}$ \\
\hline E2+E1 & $4+4$ & 4 & $50: 50$ & 1 & 1 & 3.67 & 3.69 \\
\hline E2+E3 & $4+4$ & 4 & $50: 50$ & 1 & 1 & 3.67 & 3.45 \\
\hline E2+EE2 & $4+4$ & 4 & $50: 50$ & 1 & 1 & 3.67 & 3.37 \\
\hline
\end{tabular}




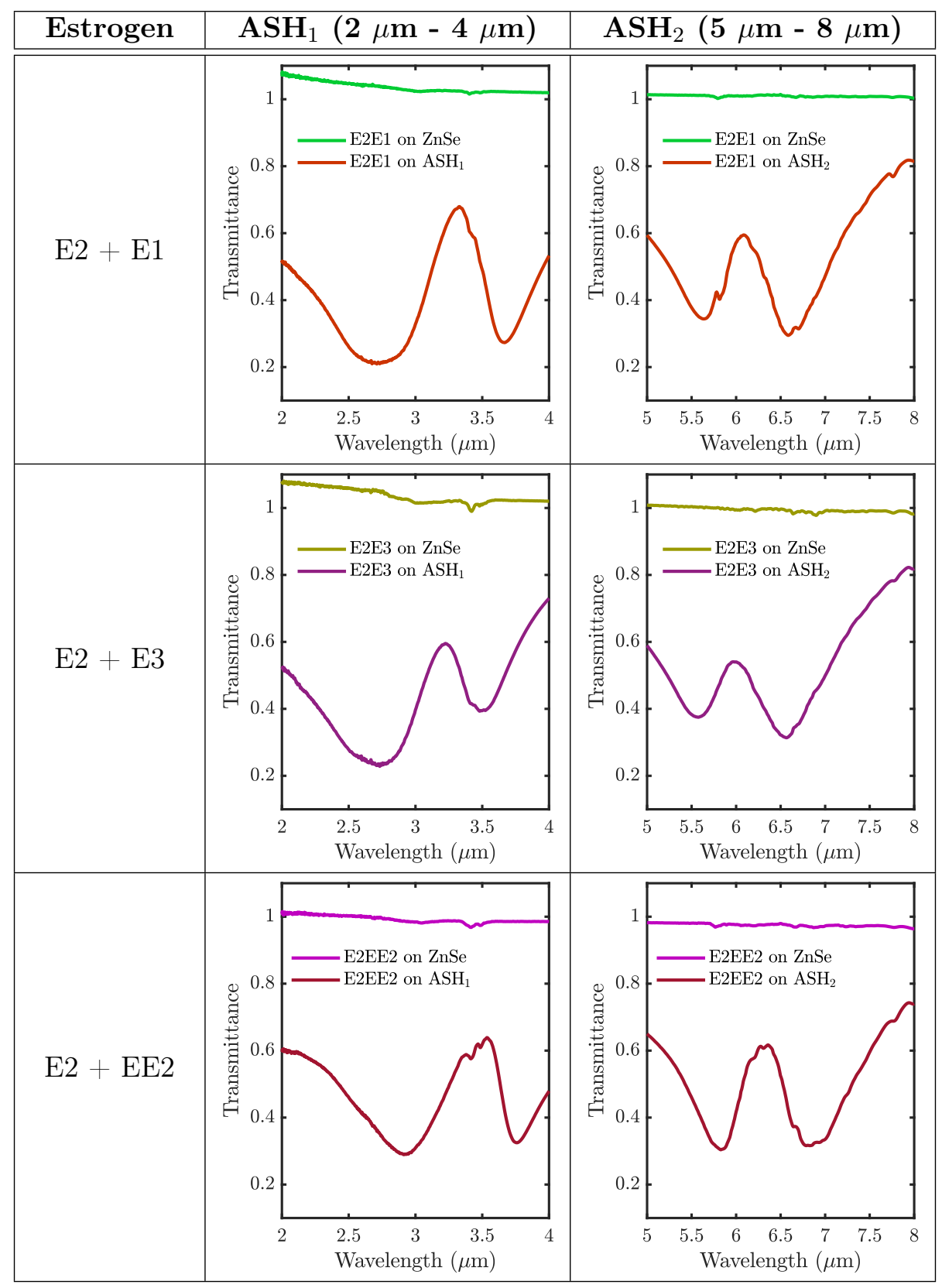

Figure A3: Plots transmittance resonances from the ASH with the mixture of E2 with E1, E3, and EE2 vibrational resonances for the $\mathrm{C}-\mathrm{H}, \mathrm{C}=\mathrm{O}$ and $\mathrm{C}=\mathrm{C}$ bonds with the inset showing the zoomed plots 
Table A3: Table of the mixtures between E2 and E1 with different ratios diluted in the absolute ethanol giving the same total concentration of $2 \mathrm{mg} / \mathrm{ml}$.

\begin{tabular}{|c|c|c|c|c|c|c|}
\hline $\begin{array}{c}\mathbf{E 2}+\mathbf{E} 1 \\
(\mathrm{mg})\end{array}$ & $\begin{array}{c}\text { EtOH } \\
(\mathrm{ml})\end{array}$ & Ratio & $\begin{array}{c}\mathbf{E 2} \\
(\mathrm{mg} / \mathrm{ml})\end{array}$ & $\begin{array}{c}\mathbf{E 1} \\
(\mathrm{mg} / \mathrm{ml})\end{array}$ & $\begin{array}{c}\mathbf{E 2} \\
(\mathrm{mM})\end{array}$ & $\begin{array}{c}\mathbf{E 1} \\
(\mathrm{mM})\end{array}$ \\
\hline $4+4$ & 4 & $50: 50$ & 1 & 1 & 3.67 & 3.69 \\
\hline $3+5$ & 4 & $37.5: 62.7$ & 0.75 & 1.25 & 2.75 & 4.62 \\
\hline $2+6$ & 4 & $25: 75$ & 0.5 & 1.5 & 1.83 & 5.55 \\
\hline $1+7$ & 4 & $12.5: 87.5$ & 0.25 & 1.75 & 0.92 & 6.47 \\
\hline $0+8$ & 4 & $0: 100$ & 0 & 1 & 0 & 7.39 \\
\hline
\end{tabular}




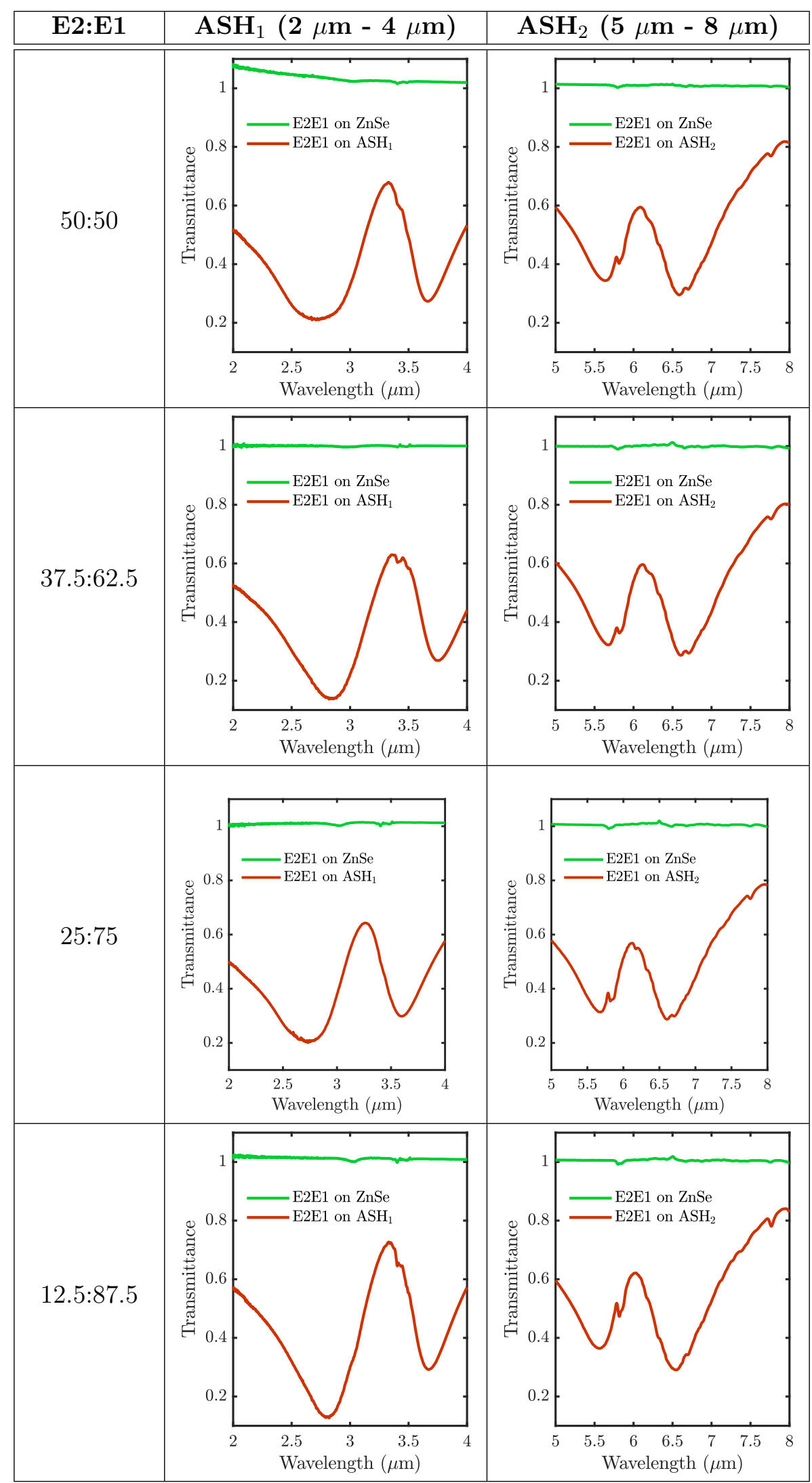

Figure A4: Plots transmittance resonances from the ASH with the mixture of E2 with E1 with different ratio. 


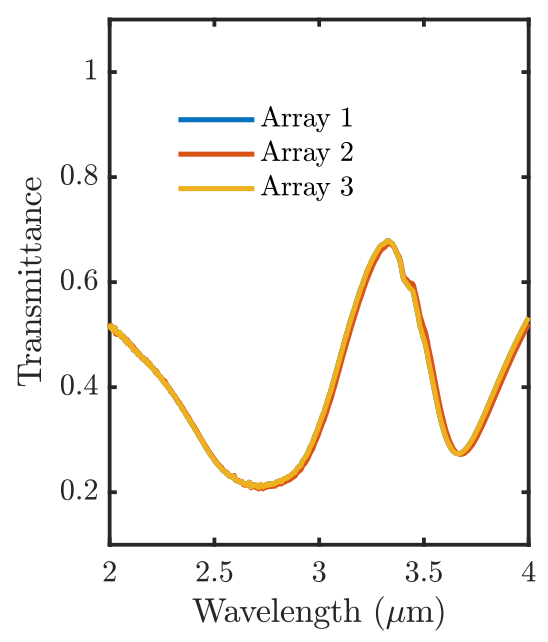

(a) $\mathrm{ASH}_{1}$

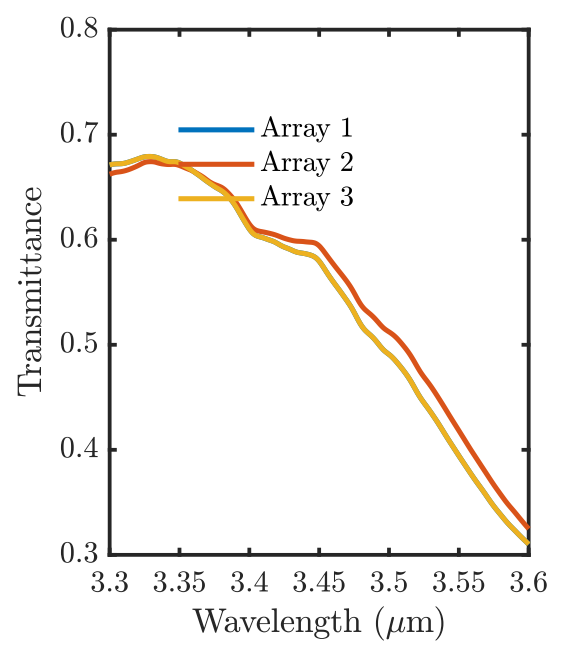

(c) $\mathrm{ASH}_{1}$

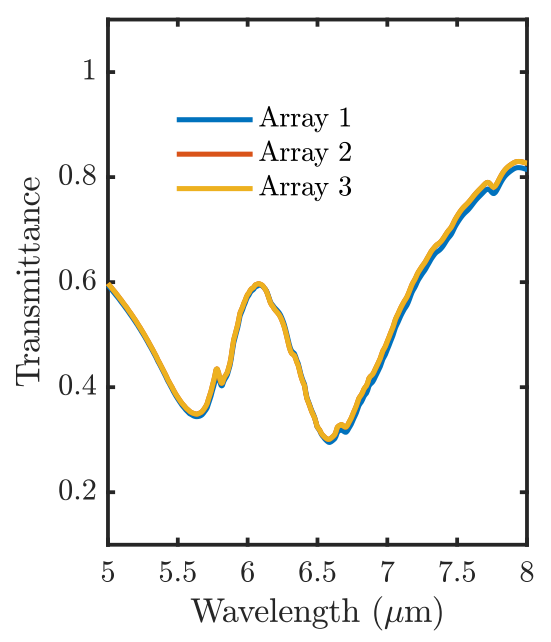

(b) $\mathrm{ASH}_{2}$

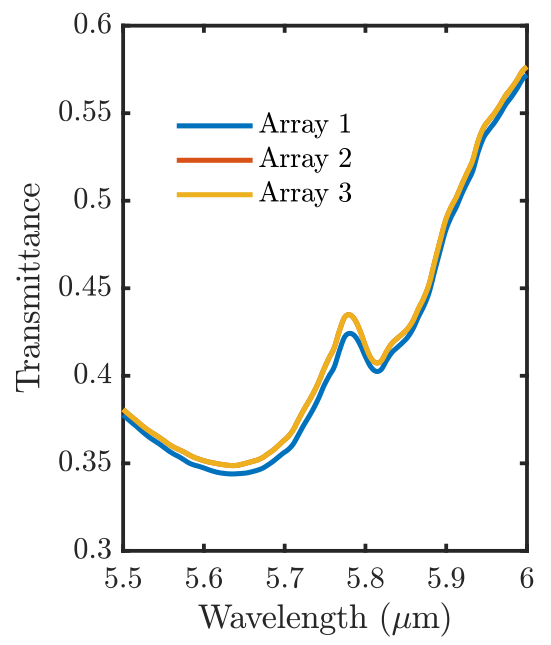

(d) $\mathrm{ASH}_{2}$

Figure A6: FTIR transmittance spectra of three arrays in a different area from samples mixtures of E2: E1 (4:4) 


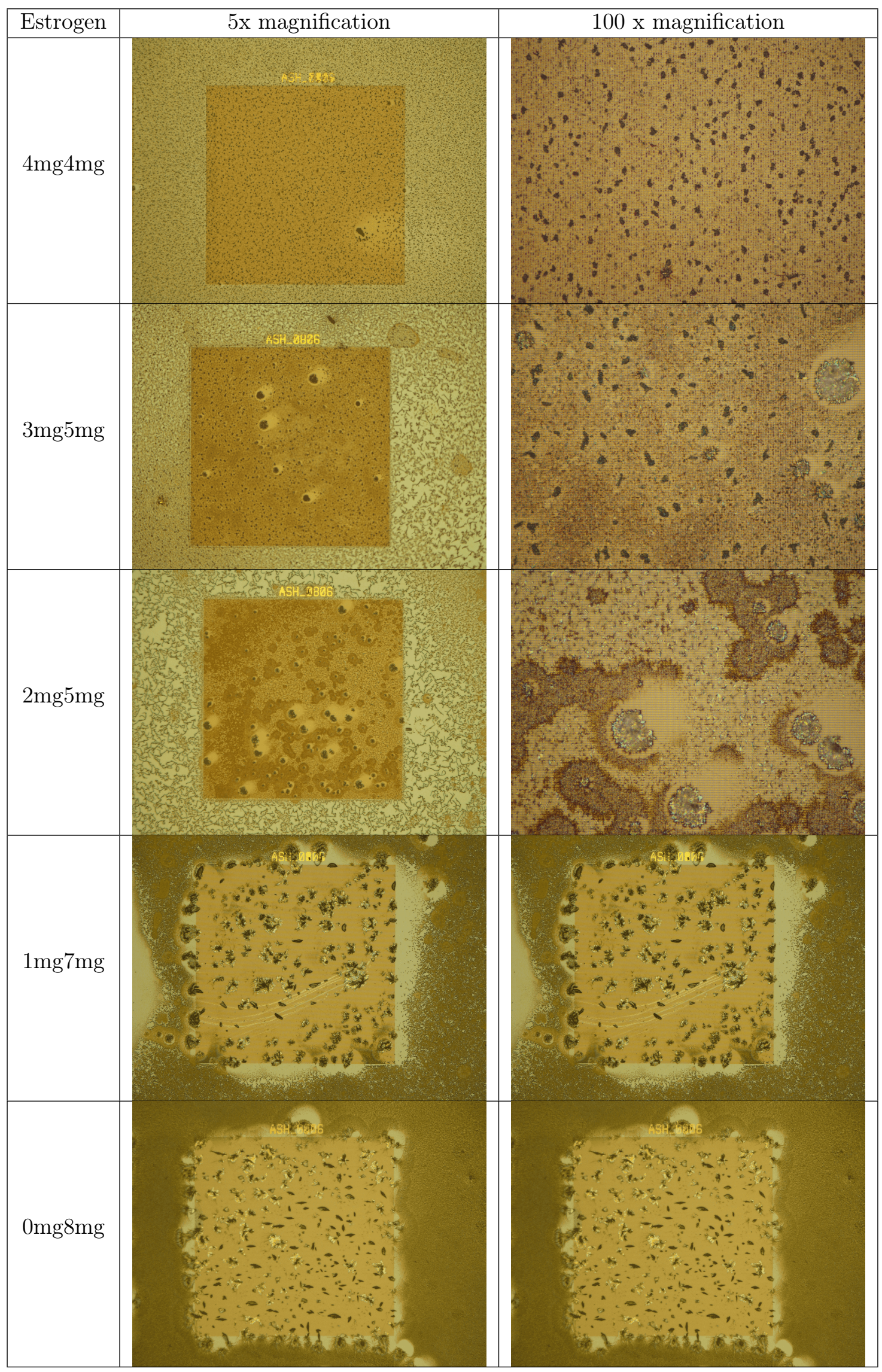

Figure A5: Microscope images of the mixture of 53 with E1 with a different ratio on the ASH arrays 


\section{References}

1. Adeel, M.; Song, X.; Wang, Y.; Francis, D.; Yang, Y. Environmental impact of estrogens on human, animal and plant life: A critical review. Environment International 2017, 99, 107-119.

2. Wise, A.; O’Brien, K.; Woodruff, T. Are Oral Contraceptives a Significant Contributor to the Estrogenicity of Drinking Water? †. Environmental Science 6 Technology 2011, $45,51-60$.

3. Chang, H.; Wan, Y.; Wu, S.; Fan, Z.; Hu, J. Occurrence of androgens and progestogens in wastewater treatment plants and receiving river waters: Comparison to estrogens. Water Research 2011, 45, 732-740.

4. Murk, A. J.; Legler, J.; Van Lipzig, M. M. H.; Meerman, J. H. N.; Belfroid, A. C.; Spenkelink, A.; Van der Burg, B.; Rijs, G. B. J.; Vethaak, D. Detection of estrogenic potency in wastewater and surface water with three in vitro bioassays. Environmental Toxicology and Chemistry 2002, 21, 16-23.

5. Nezami, A.; Nosrati, R.; Golichenari, B.; Rezaee, R.; Chatzidakis, G. I.; Tsatsakis, A. M.; Karimi, G. Nanomaterial-based aptasensors and bioaffinity sensors for quantitative detection of 17ß-estradiol. TrAC Trends in Analytical Chemistry 2017, 94, 95-105.

6. Hamid, H.; Eskicioglu, C. Fate of estrogenic hormones in wastewater and sludge treatment: A review of properties and analytical detection techniques in sludge matrix. 2012, $46,5813-5833$.

7. Velicu, M.; Suri, R. Presence of steroid hormones and antibiotics in surface water of agricultural, suburban and mixed-use areas. Environmental Monitoring and Assessment 2009, 154, 349-359. 
8. European Commission, Introduction to the new EU Water Framework Directive - Environment. 2015.

9. Sanghavi, B. J.; Moore, J. A.; Chávez, J. L.; Hagen, J. A.; Kelley-Loughnane, N.; Chou, C. F.; Swami, N. S. Aptamer-functionalized nanoparticles for surface immobilization-free electrochemical detection of cortisol in a microfluidic device. Biosensors and Bioelectronics 2016, 78, 244-252.

10. Long, F.; He, M.; Zhu, A. N.; Shi, H. C. Portable optical immunosensor for highly sensitive detection of microcystin-LR in water samples. Biosensors and Bioelectronics 2009, 24, 2346-2351.

11. Long, F.; Zhu, A.; Shi, H. Recent advances in optical biosensors for environmental monitoring and early warning. Sensors 2013, 13, 13928-13948.

12. Backe, W. J. An Ultrasensitive (Parts-Per-Quadrillion) and SPE-Free Method for the Quantitative Analysis of Estrogens in Surface Water. Environmental Science and Technology 2015, 49, 14311-14318.

13. Dai, Y.; Liu, C. Detection of $17 \beta$-Estradiol in Environmental Samples and for Health Care Using a Single-Use, Cost-Effective Biosensor Based on Differential Pulse Voltammetry (DPV). Biosensors 2017, 7, 15.

14. Huang, C.-H.; Sedlak, D. L. Analysis of estrogenic hormones in municipal wastewater effluent and surface water using enzyme-linked immunosorbent assay and gas chromatography/tandem mass spectrometry. Environmental Toxicology and Chemistry 2001, 20, 133-139.

15. Alsager, O. A.; Kumar, S.; Zhu, B.; Travas-Sejdic, J.; McNatty, K. P.; Hodgkiss, J. M. Ultrasensitive Colorimetric Detection of $17 \beta$-Estradiol: The Effect of Shortening DNA Aptamer Sequences. Analytical Chemistry 2015, 87, 4201-4209. 
16. Handbook of Hormones; Elsevier, 2016.

17. Jensen, E. V. Encyclopedia of Cancer; Springer Berlin Heidelberg: Berlin, Heidelberg, 2011; pp 1331-1333.

18. Chung, T.; Lee, S. Y.; Song, E. Y.; Chun, H.; Lee, B. Plasmonic nanostructures for nano-scale bio-sensing. Sensors 2011, 11, 10907-10929.

19. Neubrech, F.; Huck, C.; Weber, K.; Pucci, A.; Giessen, H. Surface-Enhanced Infrared Spectroscopy Using Resonant Nanoantennas. Chemical Reviews 2017, 117, 5110-5145.

20. John-Herpin, A.; Tittl, A.; Altug, H. Quantifying the Limits of Detection of SurfaceEnhanced Infrared Spectroscopy with Grating Order-Coupled Nanogap Antennas. ACS Photonics 2018, 5, 4117-4124.

21. Le, T. H. H.; Tanaka, T. Plasmonics-Nanofluidics Hydrid Metamaterial: An Ultrasensitive Platform for Infrared Absorption Spectroscopy and Quantitative Measurement of Molecules. ACS Nano 2017, acsnano.7b02743.

22. Neubrech, F.; Pucci, A.; Cornelius, T. W.; Karim, S.; García-Etxarri, A.; Aizpurua, J. Resonant plasmonic and vibrational coupling in a tailored nanoantenna for infrared detection. Physical Review Letters 2008, 101.

23. Cubukcu, E.; Zhang, S.; Park, Y.-S.; Bartal, G.; Zhang, X. Split ring resonator sensors for infrared detection of single molecular monolayers. Applied Physics Letters 2009, 95, 43113.

24. Wu, C.; Khanikaev, A. B.; Adato, R.; Arju, N.; Yanik, A. A.; Altug, H.; Shvets, G. Fanoresonant asymmetric metamaterials for ultrasensitive spectroscopy and identification of molecular monolayers. Nature Materials 2011, 11, 69-75. 
25. Lahiri, B.; Khokhar, A. Z.; De La Rue, R. M.; McMeekin, S. G.; Johnson, N. P. Asymmetric split ring resonators for optical sensing of organic materials. Optics Express 2009, $17,1107$.

26. Sharp, G. J.; Vilhena, H.; Lahiri, B.; McMeekin, S. G.; De La Rue, R. M.; Johnson, N. P. Mapping the sensitivity of split ring resonators using a localized analyte. Applied Physics Letters 2016, 108, 251105.

27. Paul, J.; McMeekin, S. G.; De La Rue, R. M.; Johnson, N. P. AFM imaging and plasmonic detection of organic thin-films deposited on nanoantenna arrays. Sensors and Actuators, A: Physical 2018, 279, 36-45.

28. Xi, M.; Reinhard, B. M. Localized Surface Plasmon Coupling between Mid-IR-Resonant ITO Nanocrystals. The Journal of Physical Chemistry C 2018, 122, 5698-5704.

29. Mbomson, I. G.; Tabor, S.; Lahiri, B.; Sharp, G. J.; McMeekin, S. G.; De La Rue, R. M.; Johnson, N. P. Asymmetric split H-shape nanoantennas for molecular sensing. Biomedical Optics Express 2017, 8, 395.

30. Gore, R. C. Infrared Spectroscopy. Analytical Chemistry 1958, 30, 570-579.

31. National Center for Biotechnology Information, Estradiol. 2004; https://pubchem.ncbi. nlm.nih.gov/compound/5757.

32. National Center for Biotechnology Information, Estrone. 2004; https://pubchem.ncbi. nlm.nih.gov/compound/5870.

33. National Center for Biotechnology Information, Estriol. 2004; https://pubchem.ncbi. nlm.nih.gov/compound/5756.

34. National Center for Biotechnology Information, Ethinyl Estradiol. 2004; https:// pubchem.ncbi.nlm.nih.gov/compound/5991. 
35. Mbomson, I. G.; McMeekin, S. G.; Lahiri, B.; De La Rue, R. M.; Johnson, N. P. Gold asymmetric split ring resonators (A-SRRs) for nano sensing of estradiol. SPIE Photonics Europe. 2014; p 912510.

36. Eilers, P. H. A perfect smoother. 2003; http://pubs.acs.org/doi/abs/10.1021/ac034173t.

37. Crystran Ltd., Zinc Selenide (ZnSe) Optical Material. 2018, 3-4.

38. Paul, J.; Sharp, G. J.; Lahiri, B.; De La Rue, R. M.; Johnson, N. P. Simulation and experimental responses of the asymmetric split ring resonators (A-SRRs) for sensing applications in the mid-infrared region. 2015 9th International Congress on Advanced Electromagnetic Materials in Microwaves and Optics (METAMATERIALS). 2015; pp 469-471.

39. Palik, E. D. Proc Natl Acad Sci USA; 1991; Vol. 2.

40. Lumerical Soultions. 2015; https://www.lumerical.com/tcad-products/fdtd/. 